\title{
The Relationship of Narrative, Virtue Education, and an Ethic of Care in Teaching Practice
}

David P. Burns and Andy Rathbone

University of Alberta

\section{Author Note}

This research was supported by the Social Sciences and Humanities Research Council.

Correspondence concerning this article should be addressed to David P. Burns, dburns@ualberta.ca

\begin{abstract}
This paper is a philosophical examination of the role of narrative in moral education. We argue that narrative, which is conceived of as a moral educational practice and not as a method, is an indispensable element of both caring moral education and virtue education. We begin by explaining the distinction we make between moral educational method and moral educational practice. Then, we outline the concept of narrative, drawn from Ricoeur and Bruner, that we seek to draw upon. After briefly outlining both care theory and virtue education, we demonstrate the value of narrative to these two divergent paradigms.
\end{abstract}

Keywords: Narrative; virtue education; care theory 


\section{The Relationship of Narrative, Virtue Education, and an Ethic of Care in Teaching Practice}

This paper is a philosophical examination of the role of narrative in moral education. We will argue that narrative, which is conceived of as a moral educational practice and not as a method, is an indispensable element of both caring moral education and virtue education. We will begin by explaining the distinction we make between moral educational method and moral educational practice. Then, we will outline the concept of narrative we wish to draw on. After briefly outlining both care theory and virtue education, we will demonstrate the value of narrative to these two divergent paradigms. Our argument is, notably, theoretical. Its chief concern is to demonstrate that the goals of care and virtue educators are mutually supported when teaching takes place in an environment in which narrative is a substantive part of moral education. The task of formulating specific activities or strategies in light of this argument will be left to educators themselves. Indeed, we shall argue that these detailed practical ideas necessarily are developed contextually in both the care and virtue educational approaches.

\section{Method and Practice}

Before we begin our discussion of what exactly narrative can provide the moral educationalist, we must first clarify the difference between a method and a practice. This distinction, it will be shown, is deeply relevant. The term method, in its popular usage, seems to indicate a kind of strategy or approach that may be picked up or put down as one pleases-perhaps being subsequently traded for a more efficacious one. One has methods for washing dishes or taking out the garbage, for example. No method is typically imbued with any particular meaning aside from its utility in accomplishing a single, given, task. Understood in this fashion method is related to techne, the Aristotelian concept powerfully contrasted with phronesis in "The Nicomachean Ethics" [NE] (trans. 1953, 1140a-1140b). It is here where the importance of this term becomes clear. Moral educationalists, it is said, do not deploy purely technical methods (techne). Rather, they engage in a dynamic, deeply contextualized form of reasoning and reflection, which Aristotle (trans. 1953) referred to as phronesis. In philosophy of education this much is fairly uncontroversial. Not even Kohlberg, the most technical of the key thinkers in 20th century moral education, would argue that moral education is exhausted by the application of technical methods. His just community (Kohlberg, 1985) proposals are, for example, deeply relational and dynamic.

This is not to say, though, that there is no such thing as techne in moral education. Indeed, contemporary character education (known for its lack of philosophical rigor) is replete with strategies, packages, and how-to guides that promise results if only they are correctly applied. A brief foray into the website of Character Counts! ${ }^{1}$ a prominent character education program, yields a wide array of token incentives, lesson plans, and other resources. To a busy teacher looking for a way to address moral development, a prepackaged method like this (complete with branded incentive materials) is a tempting solution.

A great deal more, however, is required. Much as Aristotle (trans. 1953) tied the capacity of phronesis to a person's overall virtue (in light of its use in finding the golden mean), so, too, do contemporary moral educationalists rightly tie approaches to moral education to the life of the moral educator and his or her students. Representatives of both care theory $\underline{\underline{2}}$ and virtue education ${ }^{\underline{3}}$ clearly intend to foster moral education as a way of living. Neither care nor virtue is 
conceived of as a particular package of methods to be utilized in the classroom (though each may involve particular methods).

The key point is that moral educational pedagogy must be a significant part of the life of the pedagogue, rather than merely a discrete behavior such a person engages in as part of her profession. Taking Aristotle's (trans. 1953) insight as a starting point we argue this amounts to a distinction between practices and methods. Practices, first explained in MacIntyre's (2007) famous neo-Aristotelian work, "After Virtue," prove a far more suitable categorization for moral educational teaching. Practices are, to MacIntyre, social activities we engage in that have certain internal goods and that foster and rely upon particular virtues. In one of his most notable examples, MacIntyre explains that practices like the game of chess involve certain internal goods. One comes to truly appreciate a skilled game of chess, for example, only through engaging in the practice of playing chess over time and learning the values with which chess is imbued. Chess is not played with the intent of reaching the end of the game, one could say. Rather, one engages in a game of chess for the sake of playing the game. This is why, for example, a person can enjoy a game of chess and still lose.

Something similar is the case with moral education. The goal is not simply to apply the most efficacious mechanism of moral transformation, though such mechanisms are surely relevant. Moral education is, instead, a process with internal goods, as well as certain long-term goals. By engaging in a cooperative process of reflection and action, both the teacher and the student can flourish within the practice of moral education itself. The good being realized is a moral life-here and now-not solely the promise of reaching a particular level of character or disposition in the future. The end point of such education is surely relevant, but there is an important sense in which moral educationalists hold the practice of moral education to be valuable unto itself.

Indeed, on this issue there appears to be significant agreement between care theorists and virtue educationalists. Noddings (2004), in an article directly addressing the issue of MacIntyrean practices, argues precisely this point. The heart of teaching, she argues, is in the relation between the people involved. For Noddings, it is plainly mistaken to view teaching as a process seeking a single terminal end-point. Teaching is, rather, a "never-ending moral quest" (Noddings, 2004, p. 167). Carr (1991), in his comprehensive text on virtue educational philosophy, similarly notes that there is a disturbing trend toward the emphasizing of the technical aspects of teaching, rather than the comprehensively lived good life. It is within this space of agreement that we argue narrative can contribute to moral educational life.

\section{Narrative}

Before we more fully articulate our argument, we will first outline the basis for the concept of narrative we will employ. As we do this, we will often use the related term story. Story is, in this context, meant to denote the content of one's narrative. We will begin our discussion by drawing on Ricoeur's (1992) work in this area. Ricoeur argues that character is comprised of sameness and selfhood (p. 116). Sameness refers to qualities recognized, by the individual and others, as consistent within the individual. An agent is honest, one could say, because others recognize that agent's behaviour as consistently honest. Selfhood, on the other hand, refers to the potential for change via an agent's examining a story of herself and the stories she is a part of. She may, Ricoeur argues, reflect on her selfhood and recognize that her narrative is changing over time. Such an agent may come to realize she has control over that change through her words and 
actions, and that others are implicated in this process. If she, for example, realizes that she has come to be a dishonest person in the eyes of others, it is important that she realize that her story is hers to change. This agent's story about herself, along with the way in which she is a part of the stories of others is, therefore, crucially ethically salient. Each agent's narrative is, in effect, a story about who that agent is in relation to others. The act of telling a story about a particular agent's ethical behaviour is an act that helps to define that agent's narrative identity.

This narrative identity is dependent upon the agent's memory of herself and how she perceives herself in connection to that memory, which Ricoeur (1992) explains is the paradox of identity. Personal character changes in relation to experience and the agent's interpretation of that experience. In plain terms, one is changed by events and how one reacts to them as if one were a character in a story. As this story is told and retold "it is the identity of the story that makes the identity of the character" (Ricoeur, 1992, p. 148). Ricoeur argues that, in the sense of a person being a character in a story, there is the possibility for action, communication, and a desire to change in connection to the good and through friendship with other agents. As one recognizes the value of the difference of those others, and their parallel ability to change towards a good life, one gives them a story to live up to. In so doing, one helps them to recognize their value and potential, while at the same time reaffirming one's own. In recognition of the power inherent in this process, Ricoeur (1992) argues that agents are bestowed with important ethicalnarrative responsibility (p. 165). When one creates a narrative that respects the abilities of others to change and trusts them to change towards a good life one helps to create and recreate the culture of that good life.

Bruner (1996) summarizes this view of narrative in saying, "it is through our own narratives that we principally construct a version of ourselves in the world, and it is through narrative that a culture provides models of identity and agency to its members" (p. xiv). Narrative, from this understanding, is a way of knowing that involves a moral ordering and a selection of events. What the agent remembers or includes in self-reflective stories is, thereby, a central aspect of moral life. When one says, "I want to be an honest person," one is saying something both about the importance of honesty and about its position in one's life.

Bruner (1996) helpfully demonstrates how this understanding of narrative can serve as a vehicle for education. To Bruner, education is an activity wherein we tell the stories of how we know. Teaching is a question of connecting the story of the learner to the story of the subject matter within the context of a community of other knowledge interpreters. This position seems very much in accord with the common experience of teaching. When a teacher notes that he wishes for students to see the meaning of his subject in their lives, it seems plausible to suggest that he is, at least partially, saying that he wishes for them to connect the story of his subject to their stories. On this understanding the advancement of science commonly summarized in, science texts, for example, becomes a kind of narrative with blank pages left at the end. The students, the teacher hopes, might eventually write their own pages.

Taking a more vivid example, Coles (1989) tells the story of a period of time he spent as a psychiatric resident at a hospital. During this time, one of his supervisors urged him to let his patients tell their stories. Complying with this suggestion, Coles came to realize that by allowing his patients to tell their stories, he was facilitating their recovery in ways that traditional analysis did not. In thinking about this relationship he came to conclude that in telling their stories his patients were given an opportunity to listen to themselves and that his caring (through listening) gave them a sense of self-esteem that aided their recovery. The patients were, as Ricoeur might 
say, given an opportunity to come to terms with their stories and imagine the ways in which they could change.

Drawing the conversation to a more concrete level, one finds in Ricoeur (1992) and Bruner (1996) a number of suggestions for moral educationalists. First, it seems clear that because we understand ourselves and our potential, at least partially, through a process of imagining and telling a story about ourselves, teachers must be prepared to engage with, and seriously listen to, the stories of students. In order for teachers to guide students through the difficult process of imagining a better, more ethical self, teachers must be engaged in truly listening to what students have to say about themselves and how they see their place in the world. Clearly, this suggestion carries with it a need to spend significant amounts of time with students. There are opportunities, though, where busy teachers can make the most out of their limited time. When a student engages in some form of immoral conduct - theft, for examplethere is significant moral educational value to be found in asking the student to explain what she has done and how she came to do it. It would be helpful, for example, to ask her what kind of person this sort of action makes her. It is important not to do so with the intent of simply telling the student that stealing makes you a bad person, but rather, to listen to how the student views that action within the scope of her experience. This can only be accomplished by listening to the student's story of herself.

Second, narrative can also be useful in providing a more realistic level of role modeling than is typically the case. If students are to be given a truly valuable image of what a moral life looks like, for their teachers or any other adults, the image of such persons they receive must be accurate. This means that the person they are confronted with must be shown to be an imperfect, but progressing, moral agent. Outside of the context of a rich, complex narrative of the teacher's life, such detail is difficult to present. To share elements of one's narrative with students by discussing how one views the various moral successes and failures of one's life is to engage in a deeply genuine kind of role modeling. One always has to approach such sharing delicately, though, realizing that personal sharing can be variably interpreted and that trust and familiarity are important guides to this practice. Palmer (1998) helpfully cautions that true intimacy—of the sort that produces such candid discussion — is present with only a few people in our lives.

It is critical to recognize, at this point, that these two activities need to be viewed as moral practices. Neither can be imbued with the meaning and value they are capable of holding if the teacher approaches them as methods. Both must be a part of the life of the classroom and the people who inhabit it in a way that recognizes the internal goods of the activities themselves (that is, what makes them part of a flourishing daily life). A classroom in which teachers and students take seriously the narratives they all bring to the classroom, and the narratives they create and connect during their time there, is a better, more flourishing classroom. This is, in and of itself, a morally praiseworthy accomplishment.

In our practice as teachers and learners, we have found this approach to be deeply helpful. Following Ricoeur's (1992) method of imagining oneself as the character in a story, we have encouraged students to write of their experiences and discuss how they relate to what they have read in novels, poems, and other forms of writing. This approach helps students to write themselves into the stories being discussed. When narratives are joined in this way, they bring the ideas under discussion into the life of the classroom. 
The kind of moral educational practice we envision is poised to contribute significantly not only to general moral educational pedagogy, as we have discussed thus far, but also to the specific requirements of moral education's two most vibrant and prominent paradigms: care theory and virtue education. Before this element of our argument can be advanced, however, a brief discussion of the nature of these paradigms is in order. As we begin this discussion, it is important to note that we discuss these paradigms in order to support our argument that narrative may contribute to their respective goals, not to advance either paradigm as superior.

\section{Care Theory}

Care theory is commonly attributed to Nel Noddings and Carol Gilligan. Gilligan (1982), in her text "In a Different Voice," provided the psychological basis for contemporary care theory in her discussion of women's responses to unplanned pregnancy. These women went through three stages, she argued. First, their behaviour would be dominated by caring for themselves. Then, they would develop the disposition to care primarily for others. Finally, they would come to balance care for the self and others.

From this basis, Noddings (1988) articulates the broad outlines of caring moral education. Caring, she argues, is the central aim and method of education. The caring teacher is constantly engaged in either the maintenance of caring relations or the conversion of non-caring relations to caring ones. The topic of particular lessons or conversations, in comparison, is of secondary importance (Noddings, 1994). The teacher focuses first on "engrossment (nonselective attention or total presence to the other for the duration of the caring interval) and displacement of motivation (her motive energy flows in the direction of the other's needs and projects)" (Noddings, 1988, p. 219).

In terms more specific, this involves four key activities: modeling, dialogue, practice, and confirmation (Noddings, 1988). In modeling, the teacher is constantly attempting to show students how to care by consistently engaging in caring himself. In dialogue, which Noddings (1994) describes via her concept of ordinary conversation, the teacher is called to take seriously the ideas of students and engage in non-combative, mutually affirming conversation. One must foster a strong relationship, she argues, before truly difficult conversations can be taken up. In practice, the teacher provides the students with opportunities to engage in caring themselves. Because Noddings believes that caring necessarily involves an asymmetrical relationship between the carer and cared for, opportunities to take both roles are centrally important for students. Confirmation is a process whereby a teacher seeks to affirm the most admirable part of a student. Should a student get in a fight, for example, the teacher could respond by saying "I know you wanted to protect your friend, but...”

These activities are examples of moral educational practices. Ordinary conversation, for example, is not merely a method used to foster caring in students. It is, rather, a fundamentally different way of interacting with children. Rather than treating the ideas of children as "cute," as Noddings (1994) contends teachers often do, the teacher seeks to foster a mutually respectful relation. Modeling is even more clearly tied to practice. To provide genuinely caring modeling requires a genuinely caring lifestyle, not the application of discrete caring techniques (if such a concept were even coherent on care theoretical grounds). 


\section{Virtue Education}

Virtue education has the longest history of the dominant contemporary paradigms of moral education. While Noddings' care theory dates back to the 1980s, and Kohlberg's cognitive developmentalism to the 1950s (or the Enlightenment if you trace his Kantian heritage), virtue education is typically said to have begun with Aristotle in ancient Greece. This paradigm is commonly conflated with its popularized form, character education ${ }^{4}$, but important differences

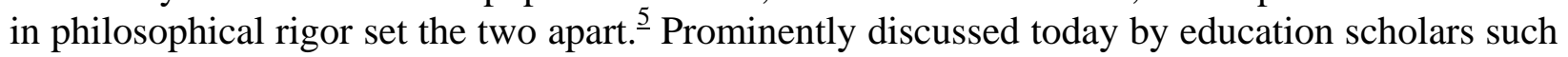
as David Carr (1991), Kristjan Kristjánsson (2000), and Jan Steutel (Steutel \& Carr, 1999), among many others, this paradigm seeks to foster growth via the cultivation of moral virtues.

Virtue education takes a broad approach to moral educational practice, seeking to address the "cognitive, conative, affective, [and] behavioural” (Steutel \& Spiecker, 1999, p. 381). As opposed to focusing solely on actions, emotions, or thought processes, virtue educationalists address the whole of one's life (Haldane, 1999). Carr (1991) summarizes the practical goal of virtue education well in noting that the goal is "seeing the point of, valuing and being favourably disposed towards certain forms of positive conduct on behalf of oneself and others” (p. 251).

This process requires learning on a number of fronts. Students must learn, for example, to discern what virtuous conduct requires in the complex contexts of actual life, and so must develop appropriate capacities for moral reasoning (namely phronesis). They must form habits that will dispose them to take virtuous actions, and so require opportunities to practice virtuous conduct. This process also involves coming to esteem such actions, and so a certain kind of Aristotelian emotional education is required whereby emotions are "harmonised with the voice of reason by their being transformed, moulded or reshaped (Steutel \& Spiecker, 2004, p. 533). ${ }^{-}$ One should, it is argued, come to feel joy at engaging in virtuous actions.

The virtue educationalist, like the care educationalist, clearly requires more than pedagogical methods. Indeed, it was with Aristotle's virtue ethics in mind that MacIntyre proposed his concept of practices. As Carr (1991) explains, "the fundamental moral virtues cannot be learned in any context of socialization or education apart from the example of those parents, teachers and friends who are able to exhibit to some degree how they work for the good in human life” (p. 9).

\section{The Contribution of Narrative}

Thus far, we have accomplished three important tasks. First, we have examined the difference between a practice and a method-emphasizing the importance of the former within moral education. Second, we have introduced a particular vision of narrative-drawn primarily from Ricoeur and Bruner-that we have characterized as a moral educational practice. Third, we have outlined the foundational ideas underpinning both care theory and virtue education. Now, building upon this foundation, we can profitably tie these pieces together.

Narrative has long been used as a method within a variety of moral educational paradigms. Character educators, for example, have always strongly emphasized the use of stories, ${ }^{-}$and research is still being done in this area today. $\stackrel{8}{ }$ Noddings (2002), in a chapter directly addressing the use of stories across moral educational paradigms, strongly endorses story-based approaches.

What becomes immediately apparent, though, is that such arguments often focus on narrative as method rather than narrative as practice. Noddings provides an excellent example. $\underline{9}$ 
Her discussions vary in focus: sometimes highlighting the efficacy of narrative and story in achieving certain discrete objectives, $\frac{10}{}$ and sometimes drawing out their more practice-oriented characteristics. ${ }^{11}$ In the former case, she notes that narrative encourages student attention, fosters awareness of key issues, and provide opportunities to build community (Noddings, 2002). These are surely important aspects of moral education and education in general. But it is at the level of practice where narrative-and scholars such as Ricoeur and Bruner-have the most to offer moral educators. It is here, we agree, that "understanding the narrative and contextual dimensions of human actors can lead to new insights, compassionate judgment, and the creation of shared knowledge and meanings that can inform professional practice" (Witherell \& Noddings, 1991, p. 8). $\underline{12}$

The form of narrative we have outlined in this paper is far more than a learning resource or lesson plan component. It is a fundamental way of relating to oneself and one's students. It is a way of viewing one's life and one's moral development. Viewed from the perspective of both care theory and virtue education, the notion of narrative as a practice holds significant potential.

Beginning with care theory, a straightforward case can be made that narrative as practice has a significant role to play. It is clear that Noddings envisions caring relations as strong bonds of mutual affirmation and understanding and that narrative is one way in which she sees this occurring (Witherell \& Noddings, 1991). Given that narrative is a part of how one views oneself, and given that a central way we affirm other people is to affirm their story, her position in this regard is compelling. The task becomes, in part, one of learning how the student sees him or herself amidst the backdrop of the story of their lives. It is only through such a process of coming to know students through the ways they talk about themselves and tell their stories that a teacher can come to know these students well enough to care effectively. One must know how and when to care, and this requires a deep understanding of a student's narrative.

In a specific sense, this contributes to understanding of the two roles Noddings (1988) envisions (carer and cared-for). Since these two roles are both necessary elements of care-ethical life, it is crucial that students be able to discuss openly the perspectives and lives of the others that join them in this ethical dyad. Students must be able to understand the experience of those that care for them so that they may respond well to that caring (an ethical imperative, argues Noddings). Similarly, students must be able to understand the life of those they care for so that they may care effectively and appropriately. It is, once again, difficult to imagine this sort of learning outside of the context of a classroom in which daily life is imbued with narrative sharing and analysis.

Indeed, when one turns to Gilligan's (1988) writing about the ethic of care one finds a remarkable level of attention to the significance of some form of narrative. She argues "if the process of coming to know others is imagined, instead, as a joining of stories, it implies the possibility of learning from others in ways that transform the self” (p. 6). Dialogue, she adds, then becomes a central vehicle for the forming and transforming of identity. Viewed from this perspective, a failure to listen and take part in narrative becomes a failure to care (p. 17).

The care-narrative connection is also evident when one begins with Ricoeur. In his development of the concept of solicitude, Ricoeur (1992) argues "it is in experiencing the irreparable loss of the loved other that we learn, through the transfer of the other onto ourselves, the irreplaceable character of our own life. It is first for the other that I am irreplaceable” (p. 193). Even within this brief passage, it is evident that Ricoeur is thinking along quite similar 
lines to care theorists. Take, Gilligan (1982), for example. Her argument that one begins with caring for others draws on similar insight. In both cases the path to recognizing the deep importance of oneself is found via one's valuing of others. The learning experience of first engaging with others is present in both cases. Care development is development through narrative, and narrative leads to care.

Turning to virtue education, it would appear that a similarly strong connection exists. Beginning with virtue-related emotional education it is clear that, in order for students to come to reflect critically on their dispositions, they need to come to understand alternative ways of living and feeling. In this regard, the guidance of the educator is central (Steutel \& Spiecker, 2004). Imbued with the practices we have outlined here, a narrative-minded educator has a number of profitable approaches before her. Kristjánsson (2005), for example, notes that having a child act out the role of a particular character with a different emotional disposition can be deeply valuable. This is, in effect, an attempt at having students take up another narrative in order to better understand their own potentialities. Kristjánsson (2005) explains, “asking an overly docile and phlegmatic child to act out the role of a properly angry person in a game, for instance, may work wonders in classroom practice; it may help children to work up steam and to channel their own anger more productively in the future” (p. 687).

On a more general level, the agent-centered nature of virtue education is such that the questions a virtue educator is apt to ask are often the very same questions one might ask in light of the requirements of narrative practice. The virtue ethicist, in contrast to the deontological ethicist, is constantly asking what particular actions say about the agent in question. What sort of character does a given action reinforce? This is, in effect, to ask how a particular event fits within the wider scope of a person's narrative.

Aristotle (trans. 1953) provides an instructive example of this point in Book I of "Nicomachean Ethics" (NE, 1100a10-1100b20). In this section, he poses a series of questions, inquiring into when it becomes possible to judge a person's flourishing. Must we wait until the end of someone's life? "Suppose that a man has lived an exceptionally happy [flourishing] life right into old age, and has ended it in like manner: many changes of fortune may befall his descendents" (NE, 1100a20-30), to what extent should it matter whether those descendents flourish or not? Does it matter if one's children turn out poorly after one dies?

In this section, Aristotle (trans. 1953) is engaging in a kind of meta-narrative conversation. He is, ultimately, asking about the scope of one's personal narrative. When does one's moral story end? What is the complete scope of one's personal narrative? His conclusion, given at 1101a15, is that there is an important role for the future in one's current ethical narrative. Your future potentialities-your selfhood, in Ricoeur's (1992) terms — are morally salient today.

At this stage, it is tempting to take the important role of narrative in both virtue education and care education and use this theoretical agreement to propose a series of concrete pedagogical activities (as we briefly did in the narrative section of this paper). While such proposals certainly have a role in moral educational scholarship, we argue that, in this case, overly concrete proposals betray, to a certain degree, the spirit of both paradigms. In both cases, the agent (in this case a teacher) is called upon to do the truly difficult ethical work of determining what the ethical theory calls for in particular circumstances. 
Aristotle (NE, 1094b) is famously insistent that virtuous conduct may only be described in broad outlines, and that the virtuous agent is virtuous in part because of her capacity to navigate the demands of her contexts. Noddings (2002) similarly argues that one must deploy a kind of care reasoning to determine what care means on a concrete level in particular contexts. Different cultures, for example, might express caring differently. While there is a great deal scholarship can contribute to the practice of virtue and care educators, both perspectives permit only broad sorts of proposals to be made. Taking the reflective resources provided in this paper and using them to come to real actions will always be difficult. Indeed, if care theory or virtue education is correct in this regard, this contextual decision making will also be the key test of an ethically praiseworthy educator.

\section{Conclusion}

We began this discussion by distinguishing method from practice. We then outlined our image of what a practice of narrative could be. This image was then demonstrated to bear relevantly upon moral education from both a care theoretical perspective and a virtue educational perspective. In both cases, the importance of personal narrative to identity and growth situated narrative practice as a key aspect of moral pedagogy. While methods of narrative and story-telling are surely valuable there is also an important need to more fundamentally address the role of narrative in day to day life inside the classroom. This need is best addressed when narrative becomes a practice in such communities. If compelling, this argument is at once hopeful and concerning. It is hopeful in the sense that narrative practice requires no special training or funding; we are all co-authors, in a sense. Much like virtue or caring in general, though, this innate potential is far from easy to cultivate. Teachers work in difficult, complex environments that are not "solely of their own choosing” (Clandinin \& Connelly, 1996, p. 136). Narrative practice asks a great deal in such circumstances - requiring sustained effort, patience, and a willingness both to listen to and to share stories and to model caring and virtue through them. Good teachers already engage in this sort of pedagogy, though, and we hope that our reflections on it here contribute to their efforts. 


\section{References}

Aristotle (1953). The nicomachean ethics (J.A.K. Thomson, Trans.). London: Penguin Books.

Bock, T. (2006). A consideration of culture in moral theme comprehension: Comparing Native and European American students. Journal of Moral Education, 35(1), 71-87.

Bruner, J. (1996). The culture of education. Cambridge, MA: Harvard University Press.

Cabot, E. L., \& Eyles, E. (1912). Stories for character training: A suggestive series of lessons in ethics. London: George G. Harrap \& Co.

Carr, D. (1991). Educating the virtues. London: Routledge.

Clandinin, D. J., \& Connelly, F. M. (1996). A storied landscape as a context for teacher knowledge. In M. Kompf, W. R. Bond, D. Dworet, \& R. T. Boak (Eds.), Changing research and practice: Teacher's professionalism, identities and knowledge. London: Falmer Press.

Coles, R. (1989). The call of stories: Teaching and the moral imagination. Boston: Houghton Mifflin.

Freire, P. (2000). Pedagogy of the oppressed (M. Bergman Ramos, Trans.). New York: Continuum.

Gilligan, C. (1982). In a different voice: Psychological theory and women's development. Cambridge, MA: Harvard University Press.

Haldane, J. (1999). Virtue, truth and relativism. In D. Carr \& J. Steutel (Eds.), Virtue ethics and moral education (pp. 155-168). London: Routledge.

Josephson Institute of Ethics (JIE). (2010). Aspen declaration on character education. Retrieved August, 2010, from http://charactercounts.org

Kohlberg, L. (1985). The just community approach to moral education in theory and practice. In M. W. Berkowitz \& F. Oser (Eds.), Moral education: Theory and application (pp. 27-88). Hillsdale, NJ: Lawrence Erlbaum Associates.

Kristjánsson, K. (2000). Teaching emotional virtue: A post-Kohlbergian approach. Scandinavian Journal of Educational Research, 44(4), 405-422.

Kristjánsson, K. (2005). Can we teach justified anger? Journal of Philosophy of Education, 39(4), 671-689.

Lickona, T. (1991). Educating for character: How our schools can teach respect and responsibility. New York: Bantam Books.

Lickona, T. (1996). Eleven principles of effective character education. Journal of Moral Education, 25(1), 93-100.

MacIntyre, A. (2007). After virtue: A study in moral theory (3rd ed.). Notre Dame, IN: University of Notre Dame Press.

McLaughlin, T. H., \& Halstead, J. M. (1999). Education in character and virtue. In J. M. Halstead \& T. H. McLaughlin (Eds.), Education in morality (pp. 132-163). London: Routledge. 
Noddings, N. (1988). An ethic of caring and its implications for instructional arrangements. American Journal of Education, 96(2), 215-231.

Noddings, N. (1994). Conversation as moral education. Journal of Moral Education, 23(2), $107-$ 118.

Noddings, N. (1996). Stories and affect in teacher education. Cambridge Journal of Education, 26(3), 435-447.

Noddings, N. (2002). Educating moral people: A caring alternative to character education. New York: Teachers College Press.

Noddings, N. (2004). Is teaching a practice? In J. Dunne \& P. Hogan (Eds.), Education and practice: Upholding the integrity of teaching and learning (pp. 159-169). Malden, MA: Blackwell Publishing.

Palmer, P. J. (1998). The courage to teach. San Francisco: Jossey Bass.

Ricoeur, P. (1992). Oneself as another. Chicago, IL: The University of Chicago Press.

Steutel, J. \& Carr, D. (1999). Virtue ethics and the virtue approach to moral education. In D. Carr \& J. Steutel (Eds.), Virtue ethics and moral education (pp. 3-18). London: Routledge.

Steutel, J. \& Spiecker, B. (1999). The good, the bad, and the pedophile. In R. Curren (Ed.), Philosophy of Education (pp. 380-388). Urbana, IL: Philosophy of Education Society.

Steutel, J. \& Spiecker, B. (2004). Cultivating sentimental dispositions through Aristotelian habituation. Journal of Philosophy of Education, 38(4), 531-549.

Witherell, C. \& Noddings, N. (1991). An invitation to our readers. in C. Witherell \& N. Noddings (Eds.), Stories lives tell: Narrative and dialogue in education (pp. 1-12).

\section{Endnotes}

${ }^{1}$ Character Counts! is a product of the Josephson Institute of Ethics (2010).

$\stackrel{2}{2}$ Noddings (1988) provides a summary of her version of care theory and its pedagogical implications.

$\underline{3}$ Carr (1991) is a foundational text in virtue education.

${ }^{4}$ Lickona $(1991 ; 1996)$ are foundational texts in character education.

${ }_{5}^{5}$ McLaughlin and Halstead (1999) delineate two forms of character education: expansive and non-expansive. Expansive character education is differentiated from non-expansive character education by, among other things, its superior level of philosophical depth.

$\underline{6}$ Aristotle $(N E, 1106 \mathrm{~b})$ directly addresses this issue in his famous passage regarding the doctrine of the mean.

${ }^{7}$ For an early $20^{\text {th }}$ century example see Cabot \& Eyles (1912).

$\stackrel{8}{8}$ Bock (2006), for example, investigates differences in character educational story comprehension between Native American and European American children. 
9 Noddings (2002) engages in a discussion of the role of story, arguing that it is appropriate to both cognitive developmental and character educational goals. While her focus is on the role of story in building community her discussion sheds considerable light on her understanding of the centrality of story to moral education in general.

10 See Noddings (2002, pp. 71-72).

11 See Noddings (1996; 2002, pp. 61-62) and Witherall and Noddings (1991).

$\underline{12}$ An example of how this process can change communication in regards to relationships of power is given in Freire (2000). 